\title{
Association between exercise and health- related quality of life and medical resource use in elderly people with diabetes: a cross- sectional population-based study
}

Chien-Cheng Huang ${ }^{1,2,3+}$, Chien-Chin Hsu ${ }^{1,4}$, Chong-Chi Chiü ${ }^{5}$, Hung-Jung Lin ${ }^{1,6}$, Jhi-Joung Wang ${ }^{7,8}$ and Shih-Feng Weng ${ }^{9,10,11,12^{*}+}$

\begin{abstract}
Background: Exercise improves glycemic control and functional capacity in elderly people with diabetes; however, its effect on health-related quality of life (HRQoL) and medical resource use remains unclear. This study aims to clarify the effect of exercise.

Methods: Using the data from National Health and Nutrition Examination Survey between 2007 and 2016, we identified 1572 elderly people with diabetes for this cross-sectional population-based study. Demographic characteristics, health conditions, comorbidities, HRQoL, and medical resource were compared among four groups (no exercise, low-intensity exercise, moderate-intensity exercise, and high-intensity exercise).

Results: The mean age of all participants was between 71.5 and 73.3 years. Male participants with higher education performed more exercise than their counterparts. The moderate- and high-intensity groups reported better general health condition than the no exercise group. Depression and worse health were more common in the no exercise group. Participants in the moderate-intensity exercise group had lower risk for depression than those in the no exercise group (adjusted odds ratio: 0.13, 95\% confidence interval: 0.02-0.92) after adjusting for demographic characteristics, health conditions, and comorbidities, whereas participants in the low- and high-intensity exercise did not have a lower risk. The no exercise group had the highest proportions of emergency, hospitalization, and total healthcare visits.
\end{abstract}

Conclusions: Exercise is associated with better HRQoL, and lack of exercise is associated with higher medical resource use in elderly people with diabetes. Encouraging exercise is recommended in this population.

Keywords: Diabetes, Elderly, Exercise, Medical resource use, Quality of life

\footnotetext{
* Correspondence: sfweng@kmu.edu.tw

${ }^{+}$Chien-Cheng Huang and Shih-Feng Weng contributed equally to this work.

${ }^{9}$ Department of Healthcare Administration and Medical Informatics, College

of Health Sciences, Kaohsiung Medical University, 100 Shin-Chuan 1st Road,

Kaohsiung 807, Taiwan

${ }^{10}$ Department of Medical Research, Kaohsiung Medical University Hospital,

Kaohsiung, Taiwan

Full list of author information is available at the end of the article
}

(c) The Author(s). 2020 Open Access This article is licensed under a Creative Commons Attribution 4.0 International License, which permits use, sharing, adaptation, distribution and reproduction in any medium or format, as long as you give appropriate credit to the original author(s) and the source, provide a link to the Creative Commons licence, and indicate if changes were made. The images or other third party material in this article are included in the article's Creative Commons licence, unless indicated otherwise in a credit line to the material. If material is not included in the article's Creative Commons licence and your intended use is not permitted by statutory regulation or exceeds the permitted use, you will need to obtain permission directly from the copyright holder. To view a copy of this licence, visit http://creativecommons.org/licenses/by/4.0/ The Creative Commons Public Domain Dedication waiver (http://creativecommons.org/publicdomain/zero/1.0/) applies to the data made available in this article, unless otherwise stated in a credit line to the data. 


\section{Background}

The world's population is aging, which affects all fields of societies, including health care system, medical expenditure, labor, finance, demands for goods and services, and family structures [1]. In the United States, elderly population (aged $\geq 65$ years) was $13.7 \%$ of the total population in 2012 and projected to be $16.8 \%$ in 2020 and $20.3 \%$ in 2030 [2]. The prevalence of type 2 diabetes is higher in elderly people. In 2011, > 25\% of elderly people have diabetes [3]. Elderly people with diabetes will have substantial microvascular and cardiovascular complications as well as increased risks for frailty, institutionalization, and mortality [3].

Different forms of exercise, including aerobic, resistance, and flexibility, are the cornerstone of diabetic management, especially in elderly people with functional decline $[4,5]$. Exercise improves glycemic control, cardiovascular function, muscle strength, and functional capacity in elderly people with diabetes $[4,5]$. Exercise is also proved to improve frailty, which is a syndrome associated with increased risks of morbidity and mortality and has higher prevalence in elderly people with diabetes than in those without $[4,5]$. Health-related quality of life (HRQoL) and medical resource use are important for elderly health care [6]. Many studies have reported the benefits of exercise for elderly people with diabetes, but the effects on healthrelated quality of life HRQoL and medical resource use remain unclear. Therefore, we conducted this study to compare HRQoL and medical resource use between elderly people with diabetes with and without exercise.

\section{Methods}

\section{Data sources}

The National Health and Nutrition Examination Survey (NHANES), a program by the National Center for Health Statistics of the Centers for Disease Control and Prevention [7], contains interviews and physical examinations and aims to assess the health and nutritional status of adults and children in the United States [7]. Given the dramatic increase in elderly population in the United States, NHANES play an important role with public health agencies to increase the knowledge of the health status of this population [7]. The interviews were conducted one person at a time at the participants' homes [7]. The study team consisted of a physician, medical and health technicians, and dietary and health interviewers [7]. The interviewers used an advanced computer system to enter data in real time [7]. The average length of an interview was $2-3 \mathrm{~h}$, but examinations varied, depending on the age of the participants [7].

\section{Study design, setting, and participants}

The estimated population proportion for the target outcome is $20 \%$, and the number of elderly people with diabetes is $12,000,000$ in the United States [8]. After calculation, the minimum number of necessary samples is 246 based on the $95 \%$ confidence interval $(\mathrm{CI})$ that the real value is within $\pm 5 \%$ of the measured/surveyed value. Using the data on diabetes from the NHANES between 2007 and 2016, we identified 1572 elderly participants for this crosssectional population-based study. Demographic characteristics (sex, age, race, education, marital status, and family poverty index ratio), health conditions (general health condition, body mass index, cigarette smoking, and alcohol drinking), comorbidities (hypertension, hypercholesterolemia, coronary heart disease, chest pain, sleep disorders, and malignancy), HRQoL (depression, worse health compared with the past year, fever in the past year, asthma attack in the past year, and visits to mental health professionals in the past year), and medical resource use (routine place to go for healthcare, doctor's office or health maintenance organization as most often place for healthcare, clinic or health center as most often place for healthcare, emergency department [ED] as most often place for healthcare, number of healthcare visits/year, hospitalized overnight in the past year, ED visit for asthma in the past year) were included for the analyses.

\section{Definitions of variables and outcomes}

The participants were categorized into following groups: (1) no exercise $(n=1119)$ : no habit of exercise; (2) lowintensity exercise $(n=195)$ : having a positive habit of exercise but have not reached the level of moderate-intensity exercise; (3) moderate-intensity exercise $(n=118)$ : at least $150 \mathrm{~min}$ of moderate aerobic activity (e.g., cycling or walking) or $75 \mathrm{~min}$ of vigorous aerobic activity (e.g., running or playing basketball) every week; and (4) high-intensity exercise: at least $300 \mathrm{~min}$ of moderate aerobic activity or $150 \mathrm{~min}$ of vigorous aerobic activity every week. Family poverty index ratio was defined as the ratio of family income to poverty [9].

\section{Ethics statement}

The NHANES is a publicly available database and approved by the National Center for Health Statistics institutional review board. All participants provided written informed consents for their participation in the NHAN ES. The current study was also approved by the Institutional Review Board of Kaohsiung Medical University (IRB number: KMUHIRB-EXEMPT(I)-20,190,033).

\section{Statistical analysis}

We used $x^{2}$ test for categorical variables and analysis of variance for continuous variables to compare demographic characteristics, health conditions, comorbidities, HRQoL, and medical resource use among the four groups. Multivariate logistic regressions were used to compare HRQoL and medical resource use among the four groups by adjusting for sex, age, race, education, marital status, general health condition, family poverty index ratio, body mass 
index, cigarette smoking, alcohol drinking, hypertension, cholesterol, chronic heart disease, chest pain, sleep disorders, and cancer. SAS 9.4 (SAS Institute Inc., Cary, NC, USA) was used for data analysis. Significance level was set at $p<0.05$ (two-tailed).

\section{Results}

The male proportion was lowest in the no exercise group (49.7\%) and highest in the high-intensity exercise group (72.1\%, Table 1). The mean \pm standard deviation ages were $73.3 \pm 5.2$ years, $72.4 \pm 4.8$ years, $72.5 \pm 5.2$ years, and $71.5 \pm 5.0$ years in the no exercise, low-intensity exercise, moderate-intensity exercise, and high-intensity exercise groups, respectively. The non-Hispanic white race was predominant among the four groups. The number of participants who had high school education or less was the highest in the no exercise group (48.1\%), whereas the number of those with college degree or higher was the highest in the other three groups. Analyses for marital status showed that the number of married participants was the highest among all groups. Self-report of general health condition as "Excellent/Very good/good" was lowest in the no exercise group (44.3\%) and highest in the moderateintensity (73.7\%) and high-intensity exercise (69.3\%) groups. The number of participants who had a body mass index of $\geq 25.0 \mathrm{~kg} / \mathrm{m}^{2}$ and smoked cigarettes were the highest in the no exercise group. The high-intensity exercise group had the highest number of alcohol drinkers (70.7\%). The no exercise group had the highest number of participants diagnosed with hypertension $(76.9 \%)$ and chest pain (31.3\%). The low-intensity exercise group had the highest number of patients with hypercholesterolemia (69.2\%) and malignancy (25.6\%). The moderate-intensity exercise group had the highest number of participants with coronary heart diseases (17.8\%), and the high-intensity exercise group had the highest proportion of individuals with sleep disorders (38.6\%).

When comparing HRQoL, the no exercise group had the highest number of participants who were depressed over the last 2 weeks (10.7\%) and who had worse health compared with the past year (17.9\%, Table 2). The highintensity exercise group had the highest number of participants who had fever (11.4\%), asthma attack (6.4\%), and visits to mental health professionals (6.4\%) in the past year; however, the differences compared with other groups were not significant.

Comparison of medical resource use showed that the proportion of routine place for healthcare visit was similar among the four groups (Table 3). The no exercise group had the highest proportions of emergency, hospitalization, and total healthcare visits: visited ED most often for healthcare (2.1\%), had $\geq 4$ healthcare visits/year (73.7\%), were hospitalized overnight in the past year (29.3\%), and visited ED for asthma in the past year (1.7\%).
Multivariate logistic regression analyses showed that the moderate-intensity exercise group had lower risk for depression over the last 2 weeks than the no exercise group after adjusting for sex, age, race, education, marital status, general health condition, family poverty index ratio, body mass index, cigarette smoking, alcohol drinking, hypertension, cholesterol, chronic heart disease, chest pain, sleep disorders, and cancer (adjusted odds ratio [AOR]: 0.13, 95\% CI: 0.02-0.92; Table 4). In the comparison of worse health between the present and past years, the moderate- and high-intensity exercise groups had lower risk than the no exercise group in the crude analysis (odds ratio [OR]: 0.52 , 95\% CI: $0.28-0.96$ and OR: $0.47,95 \%$ CI: $0.26-0.85$, respectively). However, the difference lost the significance after adjusting for sex, age, race, education, marital status, general health condition, family poverty index ratio, body mass index, cigarette smoking, alcohol drinking, hypertension, cholesterol, chronic heart disease, chest pain, sleep disorders, and cancer (AOR: 0.83, 95\% CI: 0.43-1.58 and AOR: 0.72, 95\% CI: 0.38-1.35, respectively). The highintensity exercise group had higher risk of asthma attack in the past year than the no exercise group (AOR: 2.36, 95\% CI: 1.03-5.44). The high-intensity exercise group had a trend for lower risk of overnight hospitalization in the past year than the no exercise group (AOR: 0.65 , 95\% CI: 0.40 $1.04, p=0.075$; Table 5).

\section{Discussion}

The present study showed that male participants with higher education performed more exercise than their counterparts. Participants with moderate- and highintensity exercise self-reported better general health condition than participants without exercise. Participants without exercise had the highest proportions of being overweight and cigarette smoking. Compared with exercise groups, the number of participants who reported depression over the last 2 weeks and worse health compared with the past year was higher in the no exercise group. In the comparison of medical resource use, participants without exercise had the highest proportions of emergency, hospitalization, and total healthcare visits: visited ED most often for healthcare, had $\geq 4$ healthcare visits/year, were hospitalized overnight in the past year, and visited ED for asthma in the past year. Multivariate logistic regression analyses showed that the moderate-intensity exercise group had significantly lower risk of depression over the last 2 weeks than the no exercise group. The high-intensity exercise group had significantly higher risk of asthma attack in the past year than the no exercise group. Other differences among the four groups were not significant.

The improvements of HRQoL including lower depression in participants with moderate-intensity exercise may be due to better glycemic control, increased muscle strength, increased power and functional capacity, and 
Table 1 Comparison of demographic characteristics, health conditions, and comorbidities among the four groups by descriptive analyses

\begin{tabular}{|c|c|c|c|c|c|}
\hline Variables & $\begin{array}{l}\text { No } \\
\text { exercise } \\
n=1119\end{array}$ & $\begin{array}{l}\text { Low-intensity } \\
\text { exercise } \\
n=195\end{array}$ & $\begin{array}{l}\text { Moderate-intensity } \\
\text { exercise } \\
n=118\end{array}$ & $\begin{array}{l}\text { High-intensity } \\
\text { exercise } \\
n=140\end{array}$ & $\begin{array}{l}p- \\
\text { value }\end{array}$ \\
\hline \multicolumn{6}{|l|}{ Demographic characteristic } \\
\hline \multicolumn{6}{|l|}{ Sex } \\
\hline Male & $556(49.7)$ & $88(45.1)$ & $74(62.7)$ & $101(72.1)$ & $<0.001$ \\
\hline Female & $563(50.3)$ & $107(54.9)$ & $44(37.3)$ & $39(27.9)$ & \\
\hline Age & $73.3 \pm 5.2$ & $72.4 \pm 4.8$ & $72.5 \pm 5.2$ & $71.5 \pm 5.0$ & $<0.001$ \\
\hline \multicolumn{6}{|l|}{ Race } \\
\hline Non-Hispanic white & $471(42.1)$ & $76(39.0)$ & $58(49.2)$ & $48(34.3)$ & $<0.001$ \\
\hline Non-Hispanic black & $282(25.2)$ & $61(31.3)$ & $24(20.3)$ & $26(18.6)$ & \\
\hline Hispanic (Mexican American or other) & $284(25.4)$ & $32(16.4)$ & $25(21.2)$ & $40(28.6)$ & \\
\hline Other (including multiracial) & $82(7.3)$ & $26(13.3)$ & $11(9.3)$ & $26(18.6)$ & \\
\hline \multicolumn{6}{|l|}{ Education } \\
\hline$<$ High school & $538(48.1)$ & $50(25.6)$ & $35(29.7)$ & $37(26.4)$ & $<0.001$ \\
\hline High school or equivalent & $249(22.3)$ & $46(23.6)$ & $26(22.0)$ & $25(17.9)$ & \\
\hline College graduate or above & $332(29.7)$ & 99 (50.8) & $57(48.3)$ & $78(55.7)$ & \\
\hline \multicolumn{6}{|l|}{ Marital Status } \\
\hline Married & $600(53.6)$ & $94(48.2)$ & $70(59.3)$ & $77(55.0)$ & 0.009 \\
\hline Never married & $36(3.2)$ & $11(5.6)$ & $3(2.5)$ & $11(7.9)$ & \\
\hline Widowed & $319(28.5)$ & $60(30.8)$ & $28(23.7)$ & $23(16.4)$ & \\
\hline $\begin{array}{l}\text { Living with partner, separated, or } \\
\text { divorced }\end{array}$ & $164(14.7)$ & $30(15.4)$ & $17(14.4)$ & $29(20.7)$ & \\
\hline Family poverty index ratio & $2.1 \pm 1.3$ & $2.5 \pm 1.4$ & $2.8 \pm 1.4$ & $2.5 \pm 1.5$ & $<0.001$ \\
\hline \multicolumn{6}{|l|}{ Health Condition } \\
\hline \multicolumn{6}{|l|}{ General health condition } \\
\hline Excellent/Very good/good & $496(44.3)$ & $126(64.6)$ & $81(73.7)$ & $97(69.3)$ & $<0.001$ \\
\hline Fair/Poor & $623(55.7)$ & $69(35.4)$ & $31(26.3)$ & $43(30.7)$ & \\
\hline \multicolumn{6}{|l|}{ Body mass index, $\mathrm{kg} / \mathrm{m}^{2}$} \\
\hline$<18.5$ & $9(0.8)$ & $0(0.0)$ & $0(0.0)$ & $1(0.7)$ & 0.107 \\
\hline $18.5-25.0$ & $165(14.8)$ & $43(22.1)$ & $19(16.1)$ & $28(20.0)$ & \\
\hline$\geq 25.0$ & $945(84.5)$ & $152(78.0)$ & $99(83.9)$ & $111(79.3)$ & \\
\hline Cigarette smoking & $113(10.1)$ & $13(6.7)$ & $7(5.9)$ & $99(6.4)$ & 0.144 \\
\hline Alcohol drinking & $589(52.6)$ & $102(52.3)$ & $77(65.3)$ & $99(70.7)$ & $<0.001$ \\
\hline \multicolumn{6}{|l|}{ Comorbidity } \\
\hline Hypertension & $861(76.9)$ & $147(75.4)$ & $86(72.9)$ & $96(68.6)$ & 0.149 \\
\hline Hypercholesterolemia & $693(61.9)$ & $135(69.2)$ & $71(60.2)$ & $90(64.3)$ & 0.232 \\
\hline Coronary heart disease & $193(17.3)$ & $23(11.8)$ & $21(17.8)$ & 19 (13.6) & 0.204 \\
\hline Chest pain & $350(31.3)$ & $55(28.2)$ & $27(22.9)$ & $34(24.3)$ & 0.105 \\
\hline Sleep disorders & 365 (32.6) & $70(36.9)$ & $31(26.3)$ & $54(38.6)$ & 0.159 \\
\hline Malignancy & $259(23.2)$ & $50(25.6)$ & $29(24.6)$ & $31(22.1)$ & 0.851 \\
\hline
\end{tabular}

Data are expressed as $n$ (\%) or mean \pm standard deviation 
Table 2 Comparison of HRQOL among the four groups by descriptive analyses

\begin{tabular}{|c|c|c|c|c|c|}
\hline Subtype of HRQoL & $\begin{array}{l}\text { No exercise } \\
\mathrm{n}=1119\end{array}$ & $\begin{array}{l}\text { Low-intensity exercise } \\
n=195\end{array}$ & $\begin{array}{l}\text { Moderate-intensity exercise } \\
\mathrm{n}=118\end{array}$ & $\begin{array}{l}\text { High-intensity exercise } \\
n=140\end{array}$ & $p$-value \\
\hline \multicolumn{6}{|c|}{ Depression over the last two weeks } \\
\hline Yes & $120(10.7)$ & $16(8.2)$ & $1(0.9)$ & $8(5.7)$ & \multirow[t]{2}{*}{0.002} \\
\hline No & $999(89.3)$ & $179(91.8)$ & $117(99.2)$ & $132(94.3)$ & \\
\hline \multicolumn{6}{|c|}{ Worse health compared with the past year } \\
\hline Yes & $200(17.9)$ & $24(12.3)$ & $12(10.2)$ & $13(9.3)$ & \multirow[t]{2}{*}{0.006} \\
\hline No & $919(82.1)$ & $171(87.7)$ & $106(89.8)$ & $127(90.7)$ & \\
\hline \multicolumn{6}{|l|}{ Fever in the past year } \\
\hline Yes & $99(8.9)$ & $10(5.1)$ & $10(8.5)$ & $16(11.4)$ & \multirow[t]{2}{*}{0.211} \\
\hline No & $1020(91.2)$ & $185(94.9)$ & $108(91.5)$ & $124(88.6)$ & \\
\hline \multicolumn{6}{|c|}{ Asthma attack in the past year } \\
\hline Yes & $44(3.9)$ & $6(3.1)$ & $6(5.1)$ & $9(6.4)$ & \multirow[t]{2}{*}{0.425} \\
\hline No & $1075(96.1)$ & $189(96.9)$ & $112(94.9)$ & $131(93.6)$ & \\
\hline \multicolumn{6}{|c|}{ Visit mental health professional in the past year } \\
\hline Yes & $65(5.8)$ & $10(5.1)$ & $3(2.5)$ & $9(6.4)$ & \multirow[t]{2}{*}{0.483} \\
\hline No & $1054(94.2)$ & $185(94.9)$ & $115(97.5)$ & $131(93.6)$ & \\
\hline
\end{tabular}

HRQoL Health-related quality of life

Table 3 Comparison of medical resource use among the four groups by descriptive analyses

\begin{tabular}{|c|c|c|c|c|c|}
\hline Subtype of medical resource use & $\begin{array}{l}\text { No exercise } \\
n=1119\end{array}$ & $\begin{array}{l}\text { Low-intensity exercise } \\
n=195\end{array}$ & $\begin{array}{l}\text { Moderate-intensity exercise } \\
\mathrm{n}=118\end{array}$ & $\begin{array}{l}\text { High-intensity exercise } \\
\mathrm{n}=140\end{array}$ & $p$-value \\
\hline \multicolumn{4}{|l|}{ Routine place to go for healthcare } & & 0.998 \\
\hline Yes & $1101(98.4)$ & $192(98.5)$ & $116(98.3)$ & $138(98.6)$ & \\
\hline No & $18(1.6)$ & $3(1.5)$ & $2(1.7)$ & $2(1.4)$ & \\
\hline \multicolumn{5}{|c|}{ Doctor's office or $\mathrm{HMO}$ as most often place for healthcare } & 0.122 \\
\hline Yes & $786(70.2)$ & $143(73.3)$ & $94(79.7)$ & $95(67.9)$ & \\
\hline No & $333(29.8)$ & $52(26.7)$ & $24(20.3)$ & $45(32.1)$ & \\
\hline \multicolumn{5}{|c|}{ Clinic or health center as most often place for healthcare } & 0.255 \\
\hline Yes & $243(21.7)$ & $37(19.0)$ & $18(15.3)$ & $34(24.3)$ & \\
\hline No & $876(78.3)$ & $158(81.0)$ & $100(84.8)$ & $106(75.7)$ & \\
\hline \multicolumn{5}{|l|}{ ED as most often place for healthcare } & 0.794 \\
\hline Yes & $23(2.1)$ & $4(2.1)$ & $1(0.9)$ & $2(1.4)$ & \\
\hline No & $1096(97.9)$ & $191(98.0)$ & $117(99.2)$ & $138(98.6)$ & \\
\hline \multicolumn{5}{|l|}{ Number of healthcare visits/year } & 0.339 \\
\hline $0-3$ visits & $294(26.3)$ & $58(29.7)$ & $38(32.2)$ & $43(30.7)$ & \\
\hline$\geq 4$ visits & $825(73.7)$ & $137(70.3)$ & $80(67.8)$ & $97(69.3)$ & \\
\hline \multicolumn{5}{|l|}{ Hospitalized overnight in the past year } & 0.008 \\
\hline Yes & $328(29.3)$ & $45(23.1)$ & $26(22.0)$ & $25(17.9)$ & \\
\hline No & $791(70.69)$ & $150(76.92)$ & $92(77.97)$ & $115(82.14)$ & \\
\hline \multicolumn{5}{|l|}{ ED visit for asthma in the past year } & 0.581 \\
\hline Yes & $19(1.7)$ & $1(0.5)$ & $1(0.9)$ & $2(1.4)$ & \\
\hline No & 1100 (98.3) & $194(99.5)$ & $117(99.2)$ & 138 (98.6) & \\
\hline
\end{tabular}


Table 4 Comparison of HRQoL among the four groups by multivariate logistic regression analyses

\begin{tabular}{|c|c|c|c|c|}
\hline Subtype of HRQoL & OR $(95 \% \mathrm{Cl})$ & $p$-value & AOR $(95 \% \mathrm{Cl})^{\mathrm{a}}$ & $p$-value \\
\hline \multicolumn{5}{|l|}{ Depression over the last 2 weeks } \\
\hline No exercise & 1.00 & & 1.00 & \\
\hline Low-intensity exercise & $0.74(0.43-1.28)$ & 0.288 & $1.02(0.56-1.84)$ & 0.958 \\
\hline Moderate-intensity exercise & $0.07(0.01-0.51)$ & 0.009 & $0.13(0.02-0.92)$ & 0.041 \\
\hline High-intensity exercise & $0.51(0.24-1.06)$ & 0.069 & $0.70(0.32-1.55)$ & 0.380 \\
\hline \multicolumn{5}{|c|}{ Worse health compared with the past year } \\
\hline No exercise & 1.00 & & 1.00 & \\
\hline Low-intensity exercise & $0.65(0.41-1.02)$ & 0.058 & $0.87(0.54-1.41)$ & 0.573 \\
\hline Moderate-intensity exercise & $0.52(0.28-0.96)$ & 0.038 & $0.83(0.43-1.58)$ & 0.562 \\
\hline High-intensity exercise & $0.47(0.26-0.85)$ & 0.012 & $0.72(0.38-1.35)$ & 0.301 \\
\hline \multicolumn{5}{|l|}{ Fever in the past year } \\
\hline No exercise & 1.00 & & 1.00 & \\
\hline Low-intensity exercise & $0.56(0.29-1.09)$ & 0.086 & $0.55(0.27-1.10)$ & 0.092 \\
\hline Moderate-intensity exercise & $0.95(0.48-1.88)$ & 0.892 & $1.17(0.57-2.40)$ & 0.670 \\
\hline High-intensity exercise & $1.33(0.76-2.33)$ & 0.319 & $1.57(0.84-2.91)$ & 0.157 \\
\hline \multicolumn{5}{|l|}{ Asthma attack in the past year } \\
\hline No exercise & 1.00 & & 1.00 & \\
\hline Low-intensity exercise & $0.78(0.33-1.85)$ & 0.566 & $0.86(0.34-2.14)$ & 0.740 \\
\hline Moderate-intensity exercise & $1.31(0.55-3.14)$ & 0.547 & $2.27(0.88-5.83)$ & 0.089 \\
\hline High-intensity exercise & $1.68(0.80-3.52)$ & 0.170 & $2.36(1.03-5.44)$ & 0.043 \\
\hline \multicolumn{5}{|c|}{ Visit mental health professional in the past year } \\
\hline No exercise & 1.00 & & 1.00 & \\
\hline Low-intensity exercise & $0.88(0.44-1.74)$ & 0.706 & $0.82(0.40-1.71)$ & 0.602 \\
\hline Moderate-intensity exercise & $0.42(0.13-1.37)$ & 0.151 & $0.51(0.15-1.68)$ & 0.264 \\
\hline High-intensity exercise & $1.11(0.54-2.29)$ & 0.769 & $0.97(0.44-2.11)$ & 0.932 \\
\hline
\end{tabular}

better cardiovascular function [4]. The mechanisms of better glycemic control by exercise include increases in insulin sensitivity, glucose transporter protein-4 translocation to the muscle cell membrane, glycogen synthase activity, glucose metabolism by increased muscle mass $[10,11]$, available glucose storage capacity, and glucose clearance from the circulation and reduction in visceral fat [11]. Aerobic and resistance trainings effectively reduced the glycemic levels in individuals with diabetes and even prediabetes [11-13]. A previous work suggested effective aerobic training including continuous low to moderate-intensity or intermittent high-intensity training 3-5 times per week [4]. Resistance training combining heavy and explosive loads could improve insulin sensitivity and decrease abdominal fat in elderly people with diabetes [11]. The combination of aerobic and resistance trainings is more effective to improve neuromuscular and cardiovascular functions than aerobic or endurance training alone [4]. The level of exercise intensity is also important.
Exercise is suggested to be composed of at least $150 \mathrm{~min}$ of exercise per week, and more exercise is considered be better, divided into 2 or 3 nonconsecutive days [12]. This study showed that participants with high-intensity exercise had lower depression than those without exercise; however, the difference was not significant. The possible explanation is the limited sample size. We suggest larger studies about this issue in the future.

Elderly people with diabetes have higher risk of depression than those without diabetes [14]. People with depression also have an increased risk of diabetes [15]. Depression contributes to poor compliance of diabetes management, provider-patient communication, and therapeutic effects [16]. In addition, a recent study reported that depression may accelerate cognitive decline in people with diabetes [16]. A systemic review reported that exercise appears to exert beneficial clinical effects on elderly people with depressive symptoms [17]. The guideline of National Institute for Health and Clinical Excellence also suggested structured 
Table 5 Comparison of medical resource use among the four groups by multivariate logistic regression analyses

\begin{tabular}{|c|c|c|c|c|}
\hline Subtype of medical resource use & OR $(95 \% \mathrm{Cl})$ & $p$-value & $\operatorname{AOR}(95 \% \mathrm{CI})^{\mathrm{a}}$ & $p$-value \\
\hline \multicolumn{5}{|l|}{ Routine place to go for healthcare } \\
\hline No exercise & 1.00 & & 1.00 & \\
\hline Low-intensity exercise & $1.05(0.31-3.59)$ & 0.943 & $0.80(0.21-2.99)$ & 0.737 \\
\hline Moderate-intensity exercise & $0.95(0.22-4.14)$ & 0.944 & $0.86(0.18-4.06)$ & 0.846 \\
\hline High-intensity exercise & $1.13(0.26-4.91)$ & 0.873 & $1.20(0.25-5.82)$ & 0.822 \\
\hline \multicolumn{5}{|c|}{ Doctor's office or HMO as most often place for healthcare } \\
\hline No exercise & 1.00 & & 1.00 & \\
\hline Low-intensity exercise & $1.17(0.83-1.64)$ & 0.382 & $1.09(0.76-1.58)$ & 0.640 \\
\hline Moderate-intensity exercise & $1.66(1.04-2.64)$ & 0.034 & $1.49(0.91-2.44)$ & 0.113 \\
\hline High-intensity exercise & $0.90(0.61-1.30)$ & 0.562 & $0.96(0.64-1.46)$ & 0.857 \\
\hline \multicolumn{5}{|c|}{ Clinic or health center as most often place for healthcare } \\
\hline No exercise & 1.00 & & 1.00 & \\
\hline Low-intensity exercise & $0.84(0.57-1.24)$ & 0.389 & $0.92(0.61-1.39)$ & 0.686 \\
\hline Moderate-intensity exercise & $0.65(0.39-1.09)$ & 0.105 & $0.73(0.42-1.25)$ & 0.250 \\
\hline High-intensity exercise & $1.16(0.77-1.75)$ & 0.489 & $1.10(0.70-1.73)$ & 0.682 \\
\hline \multicolumn{5}{|l|}{ ED as most often place for healthcare } \\
\hline No exercise & 1.00 & & 1.00 & \\
\hline Low-intensity exercise & $1.00(0.34-2.92)$ & 0.997 & $1.17(0.37-3.68)$ & 0.791 \\
\hline Moderate-intensity exercise & $0.41(0.16-3.04)$ & 0.382 & $0.52(0.07-4.11)$ & 0.533 \\
\hline High-intensity exercise & $0.69(0.16-2.96)$ & 0.618 & $0.81(0.17-3.85)$ & 0.786 \\
\hline \multicolumn{5}{|l|}{ Healthcare visits $\geq 4 /$ year } \\
\hline No exercise & 1.00 & & 1.00 & \\
\hline Low-intensity exercise & $0.84(0.60-1.18)$ & 0.313 & $0.91(0.64-1.30)$ & 0.601 \\
\hline Moderate-intensity exercise & $0.75(0.50-1.13)$ & 0.168 & $0.89(0.58-1.37)$ & 0.595 \\
\hline High-intensity exercise & $0.80(0.55-1.18)$ & 0.264 & $1.01(0.67-1.53)$ & 0.948 \\
\hline \multicolumn{5}{|l|}{ Hospitalized overnight in the past year } \\
\hline No exercise & 1.00 & & 1.00 & \\
\hline Low-intensity exercise & $0.72(0.51-1.03)$ & 0.076 & $0.88(0.61-1.29)$ & 0.518 \\
\hline Moderate-intensity exercise & $0.68(0.43-1.07)$ & 0.098 & $0.83(0.52-1.34)$ & 0.453 \\
\hline High-intensity exercise & $0.52(0.33-0.82)$ & 0.005 & $0.65(0.40-1.04)$ & 0.075 \\
\hline \multicolumn{5}{|l|}{ ED visit for asthma past year } \\
\hline No exercise & 1.00 & & 1.00 & \\
\hline Low-intensity exercise & $0.30(0.04-2.24)$ & 0.240 & $0.31(0.04-2.45)$ & 0.266 \\
\hline Moderate-intensity exercise & $0.50(0.07-3.73)$ & 0.495 & $0.95(0.12-7.66)$ & 0.958 \\
\hline High-intensity exercise & $0.84(0.19-3.64)$ & 0.815 & $0.92(0.18-4.64)$ & 0.918 \\
\hline
\end{tabular}

$O R$ odds ratio; $A O R$ adjusted odds ratio; $C l$ confidence interval; $H M O$ health maintenance organization; $E D$ emergency department. ${ }^{a}$ Adjusted for sex, age, race, education, marital status, general health condition, family poverty index ratio, body mass index, cigarette smoking, alcohol drinking, hypertension, cholesterol, chronic heart disease, chest pain, sleep disorders, and cancer

and supervised exercise programs for people with mild to moderate depression [18].

This study showed that participants without exercise had higher proportions of ED visit, total healthcare visit/ year, and overnight hospitalization than the three exercise groups. These findings suggest that lack of exercise may predispose elderly people with diabetes to higher risk for frailty and subsequent complications [4]. The risk of asthma attack in the past year was higher in the highintensity exercise group than in the no exercise group. Although exercise is a risk factor for asthma attack [19], respiratory exercise program was found to increase muscle strength, patient health, and quality of life [20]. Male participants with higher education performed more exercise, consistent with previous reports [21-23]. The positive association between higher education and more exercise 
suggests that education for exercise and its related benefits is important for promoting health in elderly people with diabetes.

The strength of this study is that it clarified an unclear issue by using population-based data. The limitations are as follows. First, the study adopted a cross-sectional design; as such, we could only figure out that exercise was associated with HRQoL, but the causal relationship could not be inferred. Second, the exercise level, comorbidities, HRQoL, and medical resource use were self-reported and therefore may have subjective bias. Third, the number of participants in the three exercise groups was relatively small. A higher number of participants is warranted for further investigation. Fourth, the result may not be generalized to other nations due to differences in culture, race, and medical resource.

\section{Conclusion}

This cross-sectional population-based study showed that exercise was associated with better HRQoL and lack of exercise was associated with higher medical resource use in elderly people with diabetes. Exercises including aerobic and resistance training are suggested for elderly people with diabetes. However, further studies including cohort design and more participants must be conducted to validate the results.

\section{Abbreviations}

HRQOL: Health-related quality of life; NHANES: National Health and Nutrition Examination Survey; ED: Emergency department; AOR: Adjusted odds ratio; $\mathrm{Cl}$ : Confidence interval; OR: Odds ratio

\section{Authors' contributions}

CC Huang, CC Hsu, and SFW designed the study and wrote the manuscript. SFW performed the data analysis and wrote the manuscript. CCC, HJL, and JJW provided clinical experience and wrote the manuscript. CC Huang and SFW supervised the entire study. All authors read and approved the final manuscript.

\section{Funding}

This study was supported by Grants of MOST 106-2410-H-037-015 from the Ministry of Science and Technology and 107CM-KMU-02 from Chi Mei Medical Center. The funding agency was not involved in any aspects of the study design, including data collection, data interpretation, or manuscript preparation.

\section{Availability of data and materials}

The datasets generated and/or analyzed during the current study are available in the NHANES.

\section{Ethics approval and consent to participate}

The NHANES is a publicly available database and approved by the National Center for Health Statistics institutional review board. All participants provided written informed consents for their participation in the NHANES. The current study was also approved by the Institutional Review Board of Kaohsiung Medical University (IRB number: KMUHIRB-EXEMPT(I)-20190033).

Consent for publication

Not Applicable.

\section{Competing interests}

No competing interests were declared.

\section{Author details}

'Department of Emergency Medicine, Chi Mei Medical Center, Tainan, Taiwan. ${ }^{2}$ Department of Senior Services, Southern Taiwan University of Science and Technology, Tainan, Taiwan. ${ }^{3}$ Department of Environmental and Occupational Health, College of Medicine, National Cheng Kung University, Tainan, Taiwan. ${ }^{4}$ Department of Biotechnology, Southern Taiwan University of Science and Technology, Tainan, Taiwan. ${ }^{5}$ Department of General Surgery, E-Da Cancer Hospital, I-Shou University, Kaohsiung, Taiwan. ${ }^{6}$ Department of Emergency Medicine, Taipei Medical University, Taipei, Taiwan. ${ }^{7}$ Department of Medical Research, Chi Mei Medical Center, Tainan, Taiwan. ${ }^{8}$ Allied Al Biomed Center, Southern Taiwan University of Science and Technology, Tainan, Taiwan. ${ }^{9}$ Department of Healthcare Administration and Medical Informatics, College of Health Sciences, Kaohsiung Medical University, 100 Shin-Chuan 1st Road, Kaohsiung 807, Taiwan. ${ }^{10}$ Department of Medical Research, Kaohsiung Medical University Hospital, Kaohsiung, Taiwan. ${ }^{11}$ Center for Big Data Research, Kaohsiung Medical University, Kaohsiung, Taiwan. ${ }^{12}$ Center for Medical Informatics and Statistics, Office of R\&D, Kaohsiung Medical University, Kaohsiung, Taiwan.

Received: 22 August 2019 Accepted: 31 August 2020

Published online: 07 September 2020

\section{References}

1. United Nations. Ageing. Accessed from https://www.un.org/en/sections/ issues-depth/ageing/ on April 18, 2019.

2. United States Census Bureau. An Aging Nation: The Older Population in the United States. Accessed from https://www.census.gov/content/dam/Census/ library/publications/2014/demo/p25-1140.pdf on April 18, 2019.

3. Kirkman MS, Briscoe VJ, Clark N, Florez H, Haas LB, Halter JB, Huang ES, Korytkowski MT, Munshi MN, Odegard PS, Pratley RE, Swift CS. Diabetes in older adults. Diabetes Care. 2012;35:2650-64.

4. Cadore EL, lzquierdo M. Exercise interventions in polypathological aging patients that coexist with diabetes mellitus: improving functional status and quality of life. Age (Dordr). 2015;37:64.

5. Diabetes Canada Clinical Practice Guidelines Expert Committee, Sigal RJ, Armstrong MJ, Bacon SL, Boulé NG, Dasgupta K, Kenny GP, Riddell MC. Physical Activity and Diabetes. Can J Diabetes. 2018:42:S54-63.

6. Klompstra L, Ekdahl AW, Krevers B, Milberg A, Eckerblad J. Factors related to health-related quality of life in older people with multimorbidity and high health care consumption over a two-year period. BMC Geriatr. 2019;19:187.

7. Centers for Disease Control and Prevention. National Health and Nutrition Examination Survey. Accessed from https://www.cdc.gov/nchs/nhanes/ about_nhanes.htm on April 18, 2019.

8. National Diabetes Statistics Report, 2017. Estimates of diabetes and its burden in the United States. Accessed from https://dev.diabetes.org/sites/ default/files/2019-06/cdc-statistics-report-2017.pdf on February 9, 2020.

9. National Health and Nutrition Examination Survey. 2011-2012 Data Documentation, Codebook, and Frequencies. Accessed from https://wwwn. cdc.gov/nchs/nhanes/2011-2012/demo_g.htm on April 18, 2019.

10. Ebeling P, Bourey R, Koranyi L, Tuominen JA, Groop LC, Henriksson J, Mueckler $M$, Sovijärvi A, Koivisto VA. Mechanism of enhanced insulin sensitivity in athletes. Increased blood flow, muscle glucose transport protein (GLUT-4) concentration, and glycogen synthase activity. J Clin Invest. 1993;92:1623-31.

11. Ibañez J, Izquierdo M, Argüelles I, Forga L, Larrión JL, García-Unciti M, Idoate F, Gorostiaga EM. Twice-weekly progressive resistance training decreases abdominal fat and improves insulin sensitivity in older men with type 2 diabetes. Diabetes Care. 2005;28:662-7.

12. Umpierre D, Ribeiro PA, Kramer CK, Leitão CB, Zucatti AT, Azevedo MJ, Gross $J$, Ribeiro JP, Schaan BD. Physical activity advice only or structured exercise training and association with $\mathrm{HbA1c}$ levels in type 2 diabetes: a systematic review and meta-analysis. JAMA. 2011;305:1790-9.

13. Geirsdottir OG, Arnarson A, Briem K, Ramel A, Jonsson PV, Thorsdottir I. Effect of 12-week resistance exercise program on body composition, muscle strength, physical function, and glucose metabolism in healthy, insulin-resistant, and diabetic elderly Icelanders. J Gerontol A Biol Sci Med Sci. 2012;67:1259-65.

14. Anderson RJ, Freedland KE, Clouse RE, Lustman PJ. The prevalence of comorbid depression in adults with diabetes: a meta-analysis. Diabetes Care. 2001;24:1069-78.

15. Eaton WW, Armenian H, Gallo J, Pratt L, Ford DE. Depression and risk for onset of type II diabetes. A prospective population-based study. Diabetes Care. 1996;19:1097-102. 
16. Park M, Reynolds CF. Depression among older adults with diabetes mellitus. Clin Geriatr Med. 2015;31:117-37.

17. Kim DJ. Effects of physical activity on depression in adults with diabetes. Osong Public Health Res Perspect. 2018;9:143-9.

18. National Institute for Health and Clinical Excellence. Depression: the treatment and management of depression in adults [updated edition] Leicester: British Psychological Society; 2010

19. Braman SS. Asthma in the elderly. Clin Geriatr Med. 2003;19:57-75.

20. Gomieiro LT, Nascimento A, Tanno LK, Agondi R, Kalil J, Giavina-Bianchi P. Respiratory exercise program for elderly individuals with asthma. Clinics (Sao Paulo). 2011;66:1163-9.

21. Trost SG, Owen N, Bauman AE, Sallis JF, Brown W. Correlates of adults' participation in physical activity: review and update. Med Sci Sports Exerc. 2002;34:1996-2001.

22. Trost SG, Pate RR, Sallis JF, Freedson PS, Taylor WC, Dowda M, Sirard J. Age and gender differences in objectively measured physical activity in youth. Med Sci Sports Exerc. 2002;34:350-5.

23. Saint Onge JM, Krueger PM. Education and racial-ethnic differences in types of exercise in the United States. J Health Soc Behav. 2011;52:197-211.

\section{Publisher's Note}

Springer Nature remains neutral with regard to jurisdictional claims in published maps and institutional affiliations.

Ready to submit your research? Choose BMC and benefit from:

- fast, convenient online submission

- thorough peer review by experienced researchers in your field

- rapid publication on acceptance

- support for research data, including large and complex data types

- gold Open Access which fosters wider collaboration and increased citations

- maximum visibility for your research: over $100 \mathrm{M}$ website views per year

At BMC, research is always in progress.

Learn more biomedcentral.com/submissions 